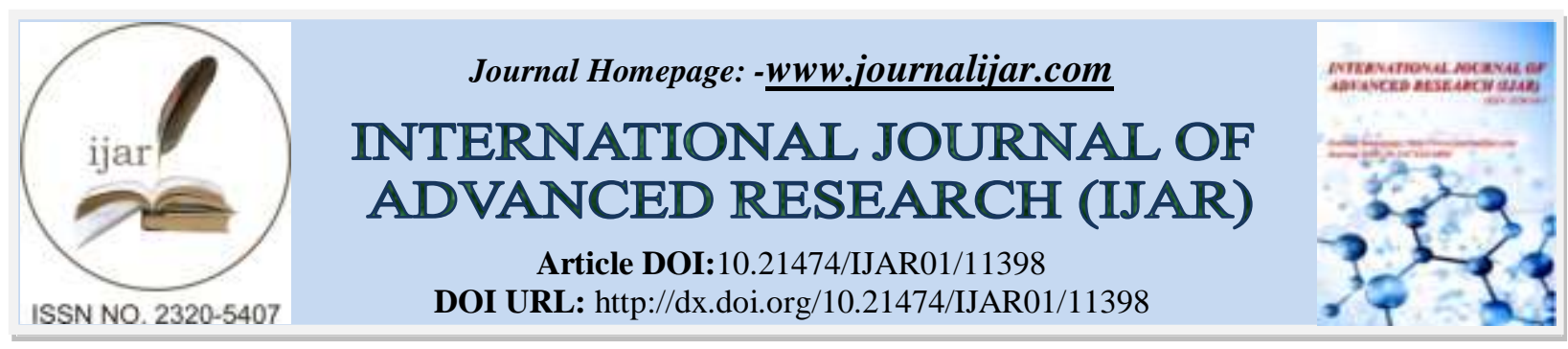

RESEARCH ARTICLE

\title{
A JOURNEY TO YOUTH IN OLD AGE: AN INTRINSIC CASE OF SUCCESSFUL AGING
}

Janet Presnilla-Espada

Leyte Normal UniversityP. Paterno St. Tacloban City, Philippines.

\section{Manuscript Info}

Manuscript History

Received: 25 May 2020

Final Accepted: 28 June 2020

Published: July 2020

Key words:-

Successful Aging, Covid-19 Pandemic, Intrinsic Case Study, Philippines

\begin{abstract}
Recent studies portray significant paradoxes about perspectives and realities of aging. Amid threats of the Covid-19 pandemic, global unrest and rapid aging, some useful practices have been proven to meet successful aging (SA). Supported by the Activity and Continuity Theories of Aging, this intrinsic case study explored the inimitable journey of an 80-year old man towards successful aging. Using content analysis (Berelson, 1952) of a three-year period of observations, artifacts, archival records and in-depth interviews of the main participant, his relatives and friends, the primary data generated four themes that contribute to SA: 1) inner strength 2) stable relationship; 3) quality social interactions; and 4) continuity of youth practices and habits. The study proposes that successful aging is a creative experience unique to every human in every culture and context.
\end{abstract}

Copy Right, IJAR, 2020,. All rights reserved.

\section{Introduction:-}

In the face of the Covid-19 pandemic, many young people today are facing the threat of failing to reach old age or reaching old age with severe and debilitating diseases (Koff and Williams, 2020). Five years ago, UNESCO (2015) declared that the world's population was rapidly aging and predicted a steady increase in the number of older persons. Today, a new pattern has emerged. Humanity is vanishing at lightning speed and that includes everyone, young and old due to the Covid-19 pandemic (UNESCO, 2020). What is most alarming is the fact that Covid-19 is severely affecting older people's lives in all aspects (Pelicioni, 2020).

However, it is worth noting that humanity has always struggled to reach successful aging in the past decades (Cosco, Prina, Perales, Stephan, and Brayne, 2014). This may be attributed to the pleasure principle, a term used by Sigmund Freud to characterize human tendency to desire pleasure and avert pain. Freud argues that people will go to extremes to avoid even the slightest pain, in particular, when facing physical or psychological threat (Akhtar and O'Neil, 2018). This human behavior, according to Eckhart Tolle (2008) is man's egoic nature which stems from the most fundamental fear of death or annihilation. Since death is inevitable, man is left with a consoling choice- that is, to at least reach old age with less or no physical or psychological pains. Scholars call this state 'successful aging' (Rowe and Khan, 1997).

\section{What is successful aging?}

Rowe and Khan (2015) who first pioneered a model, proposed successful aging (SA) as being free from disease and disability; possessing high cognitive and physical functioning and active engagement with life. Similar studies link SA to older people's quality social participation, the absence of disease and physical disability and independence in 
activities of daily living (Carver and Buchanan,2016).). Other authors define SA as wellbeing equated with happiness, contentment in old age, social pension and income (Chiao, Weng and Botticello, 2011; Sanchez, 2019).

One of the two studies that used Rowe's and Kahn's SA model defined SA as a state of being active, happy, dignified, healthy and aging productively (Sanchez, 2016) while for another it means having a low riskof disease but not in mental-physical function and engagement(Willcox, Chen, Masaki, Willcox, Allsopp and Donlon, 2018).The two studies complement each other but their varying contexts and measures prevent them from generating exactly the same results (Cosco, et al. ,2014). This suggests that the intercultural diversities and similarities in approaching SA are intervening factors that hinder scholars from generating a universal framework in defining successful aging.

\section{Diverse views on successful aging:}

The issue on successful aging (SA) has long been debated, examined and discussed in the area of gerontology- a term referring to an inclusive examination of aging and the problems associated with the aged (Kernisan, 2016). The following discussions illustrate various ways in which Asians and Westerners view SA.

One Asian study asserts that Rowe's and Kahn's SA model is lacking when applied to developing countries where access to health care is often limited such as Asian cultures that espouse a holistic view of health and wellness (Cheng, Fung, Li, Li, Woo and Chi, 2015). In line with this, Cheng, Li, Woo, Chi and Fung (2015) noted that Western SA models focus on individual responsibility and agency, while Asian cultures value collaboration and avoid individualistic paradigms.

However, the Asian authors express concern over the demographic changes occurring in Asian family systems due to industrialization and modernization. Cheng (2015) predicts that Asians will likely face the challenges of aging before they reach economic, technological and educational advancement resulting in an upsurge of older workers in the labor force affecting maintenance of work performance (Yeung and Ho, 2015). The authors are suggesting that preserving and strengthening family structures can prevent or lessen the inevitable consequences of economic expansion.

One author noticed that older Chinese have better health than their precedents with some variations in urban and rural areas, regions, socioeconomic strata and gender but found unequal distribution of opportunities for SA causing the socially disadvantaged groups to suffer the negative impact of rapid urbanization (Li and Zhang, 2015). Moreover, the fluctuating economy in Korea has increased poverty rates, gender inequality in terms of economic resources, and high suicide rate among the elderly (Kang and Kim, 2015). Considering this issue, many scholars are now advocating for government policies that support the elderly and promote the perpetuation of traditional family roles.

Meanwhile, Western scholars are not fully convinced that Asian Confucian values and filial piety can lead to positive attitudes towards aging because aging and socioeconomic development may influence aging attitudes more than shared cultural values (Löckenhoff, Lee, Buckner, Moreira, Martinez and Sun, 2015). The West authors'opposing views against claims that Asians are more likely to attain successful aging more than the Westerners are based on the premise that cultural effects are relative and may differ across individual cultures and specific aspects of aging beliefs.

\section{Factors affecting successful aging:}

A number of researches show that motivational reserve, age, physiological factors, educational attainment, income, emotional well-being, and quality of physical and cognitive functioning and high level of resilience are factors that affect successful aging (Thoma, Kleineidam, Maercker Maier and Wagner, 2017; Cosco, Stephan, Brayne, Muniz, and Cfas, 2017; Goveas, Rapp, Hogan, Driscoll, Tindle, Smith and Yaffe, 2016).

Other studies attribute influences like religious involvement (Guyette (2018); agility and mobility; taking prescribed treatments (Anton, Woods, Ashiza wa, Barb, Buford Carter and Dotson, 2015) and self-perception of health status to successful aging (Garcia, Navarrete, Medina, Aguilar and Avila (2017). Garcia and others argue that a person's perception of one's own health may induce the manifestation of perceived health symptoms in one's own body. This suggests that if older adults think of themselves as healthy, the symptoms of good health are likely to manifest. It is, therefore, important to safeguard older adults' mental health. 
Meanwhile, Sanchez (2016) found that successful aging is influenced by community and family harmony, healthy lifestyle, spirituality, participation and social position as well as government aid. Sanchez reported that social isolation is a deterring factor in attaining successful aging, followed by health problems and financial security. These findings suggest that social distancing during the Covid-19 pandemic will likely worsen many older persons' existing social isolation problems.

\section{Attaining successful aging:}

There is no perfect formula for attaining successful aging but some studies offer methods by which it can be addressed.

A group of authors propose dietary patterns for maintaining cardiovascular and bone health based on Mediterranean Diet specifying restriction of saturated fats and salt, adequate protein, calcium, vitamin D and C intake to maintain the ideal body weight values (Lok, Chan and Woo, 2015). They also advise taking in soya beans, tea, and black rice to promote healthy cells. They believe that being mobile, independent and properly nourished can maintain muscle mass and function.

Others propose active physical exercise, proper diet and continuous engagement in cognitive activities to preserve brain function and prevent dementia (Lam and Chan, 2015; Lin, Hsieh, Cheng, Tseng, and Su, 2016). The authors underscore the fact that psychomotor speed, attention and memory tend to decline with age. In addition, there is a wide individual variation in the cognitive trajectories across life spans. While neurodegenerative diseases lead to progressive intellectual impairment and loss of meaning, it has also been proven that lifestyle factors can modify cognitive function in later life (Woo, Yau and Yu, 2015).

Katagiri and Wakui (2015) recommend family social support and positive family influences on older adults' physical and mental health. They promote discussions on family care and effects of social factors on families, complex relationships and difficulties caused by current caregiving for older adults. For the older workers, Calasanti (2015) recommends job crafting as a method to help the elderly adjust their job to inner changes influenced by the aging process. An older person's proactive attitude towards changing a task to cater to relational boundaries of work can increase motivation and output production (Calasanti, 2019: Calasanti and Giles, 2018; Repetti and Calasanti, 2018)

Using grounded theory, the "Road to Success Model" proposes 5 phases in attaining successful aging such as: Struggling, Remotivating, Reforming, Reintegrating and Sustaining (Lucas, Lozano, Valdez, Manzarate and Lumawag, 2018). The authors reported that despite prison conditions, the incarcerated women participants experienced acceptance, support and engagement in the adaptation process as a motive to attain spiritual, mental and emotional well-being.

Lastly, Lasch (2018) noted that narcissism can act as a social strategy to gain security and sense of self. He points that a person can resort to religious and psychological practices to reach psychological states where one experiences peace, harmony and transcendence. Carter and Douglas (2018) link sub-clinical narcissism to mental and physical health and even longevity. Their study implies that a certain degree of narcissism is useful in the psychological functioning linked to age-related loneliness and is found to protect mental health. This finding aligns with an observation that despite chronic illness, participants who filed positive self-reports recovered faster than the normal period (Tzioumis, Avila and Adair, 2019).

\section{Theories:}

This study is anchored on two psychosocial theories of aging: Havighurst's (1961) Activity Theory and Maddox's (1968) Continuity Theory of Aging.

The Activity Theoryof Aging, developed by Robert J. Havighurst in 1961, also known as the Implicit Theory, Normal Theory and Lay Theory of Aging (Havighurst, 1963) proposes that successful aging arises when older adults maintain an active social life. It is based on the premise that dynamic shared interactions delay the aging process and boost man's quality of life. In 1964, Bernice Neugarten promoted the ideology that it is only through well-preserved personal relationships and endeavors that a person will find pleasure and satisfaction in old age (Loue, 2008). One author advocates that activities enable older adults to adjust to the realities of retirement (Tamborini and Kim, 2020). This premise sets the stage for unfolding the main participant's life that is centered on 
enduring activities that usher him to a path where aging becomes a pleasant daily experience free from the pains of the past and anxious anticipation of the future.

Meanwhile, the Continuity Theory of Aging, first described by George L. Maddox in 1968 proposes that older adults will likely keep the same activities, routines, relationships and behavioral patterns in their earlier lives by adapting strategies that are linked to their past experiences. It also defines how people evolve in old age and focuses on the individual person's efforts to obtain and sustain a state of inner peace, balance and harmony.

Historically, the continuity theory stemmed from a longitudinal study of a large number of older adults who showed consistency in their personalities, activities, behavior patterns, and relationships amid changes in physical, mental, economic and social status (Schul, Noelker, Rockwood andSprott, 2006). Since the time it was proposed and developed by Atchley $(1971 ; 1989 ; 1999)$ scholars have taken interest on how humans adapt to situations in various creative ways just to meet their goals.

In applying the theory, the current study will examine how the main participants' internal structures (personalities, beliefs, convictions) served as a guide in making his future decisions and how his external structures such as relationships and social roles helped strengthen his stable self-concept and lifestyle.

\section{The Problem:}

The heterogeneous contexts of SA studies pose a challenge in crafting a framework that can holistically define SA. The methods used in the preceding studies are mostly quantitative and the cohorts do not represent all categories of older adults. Although the problem is experienced on a global scale, findings reflect a smaller percentage of Western and Asian countries. The lack of qualitative studies of single individuals who experienced successful aging is missing in the literature.

Longitudinal studies of single individuals which may be generalizable to other contexts can add value to existing data because they can generate individualized interventions that will promote successful aging across cultures. Unearthing the latent meanings of an individual's unique journey to youth in old age can inspire millions of people whose inner power to lessen suffering in old age remains untapped.

It is from this context that this intrinsic case study is conducted. It explores the inimitable journey of an 80-year old man who claims to have attained successful aging amid various life crises that may have driven others to depression or suicide. It answers one main question: Which factors, events and circumstances contributed to the main participant's unique way of attaining successful aging? The interest of this study lies particularly on explaining why at his old age, he still exudes zest for life and deep enthusiasm like a teenage lad.

\section{Methods and Materials:-}

This section highlights the design, participants, ethical considerations, data collection and validity procedures, reflexivity and data analysis.

\section{Design of the Study:}

The method used is an intrinsic, longitudinal case study whose basic purpose is to explore a case (e.g., specific group, occupation, department, organization) where the case itself is of primary interest in the investigation (Stake, 2005; Baxter and Jack, 2008). It seeks to understand the uniqueness of the case (Hancock, 2016) without necessarily examining or creating general theories or in generalizing findings to broader populations. In this study, it focuses on an 80-year old man's experiences and qualities that shaped his life and made him one of the happiest old men in his contemporary times even during the Covid-19 pandemic.

\section{Participants' Portrait and Context:}

The main subject of interest is an 80-year old man who thinks, dresses and behaves like a teenager since early age and up to the present. He exudes extraordinary optimism and youthful aura and views his daily life more positively than his contemporaries do. He lives with his life partner whom he considers his 'beloved wife' but who is not legally married to him. She lost her hearing in her forties; thus, she is silent most of the time. The old, Spanish house where he lives belong to the deceased eldest sister of his wife and it has a store run by his wife. The rest of the participants include his wife's niece and 2 grandsons who lived with them for a long time; his 3 closest friends in the neighborhood and a tenant who has been renting a small space in front of their store for 7 years. Utilizing purposive 
sampling, the following criteria in the selection process were applied: must have a wide range of familiarity with the main participant; is able to express one's self orally and must be willing to participate in the study (Baxter, et al. 2008). All participants agreed to sign the informed consent before the conduct of the study and allowed the researcher to record the interviews and take pictures and videos for analysis.

\section{Data Collection and Validity Procedures:}

Data collection used triangulation where in-depth interviews, documents and observations were combined to substantiate the narratives of the participants (Ridder, 2017; Flick, 2018). Examining archival records such as old photos, wardrobe and accessories helped to identify the main participant's daily routines and interactions that led to a deeper understanding of the meanings of the narratives provided by the rest of the participants.

Prior to obtaining informed consent, I oriented the participants on the purpose of the study assuring them of the confidentiality of their data. I obtained demographic profile using a questionnaire specifying their age, gender, and number of years they spent with the main participant. I conducted audio-recorded, semi-structured face-to-face interviews using open-ended questions. Using their home language, participants were able to provide rich details of their accounts (Grinstead, 2005). The interviews lasted from thirty (30) to ninety-minutes and were transcribed verbatim. The participants were visited again for additional information and confirmation of transcribed data and initial conceptual analytic views.

Informal or covert observations were done for more than ten years prior to the actual conduct of the study beginning in 2017 (Flick, 2018). This was conveniently possible since the vehicle where I ride every morning to go to work stops beside the store where the main participant usually sits or stands every morning at around 7:00 o'clock or earlier. During stopovers, I would literally get a close up view of the main participant and observe for about 2 minutes during the weekdays and even on weekends whenever possible. I took note of his appearance, movements and interactions with customers and bystanders at the store. These frequent observations were very useful in supporting the data generated from the interviews. Even during the Covid-19 pandemic, I continued to gather data and pictures about his daily activities and how he was coping with the pandemic restrictions via online messaging. Due to limited knowledge in using gadgets, his grandson assisted him in the online communication.

\section{Ethical Considerations:}

Despite the convenience that covert observations offer due to the open, public and unstructured space where the researcher can gather data without influencing the field and where consent may not be possible, participants' rights to privacy should still be honored. Thus, I sought the consent of the main participant to observe him covertly for the past three years assuring him that the data will be guarded with confidentiality (Creswell, 2014).

In using the informed consent form, I indicated the purpose, nature and process of the study including the time needed for collecting data. The interview guide considered their age, background, culture and interests. I held the interviews and observations at a time and place convenient to the participants and assigned pseudonyms when reporting data. Despite request from the main participant to post his pictures on Facebook, I politely declined to protect him from possible cyber abuse (Orb, Eisenhauer and Wynaden, 2001).

\section{Reflexivity:}

As a researcher I had to know where I stand in relation to the participants and the readers (Ashmore, M. (1989). Hence, at the onset of the study I declared and bracketed my assumptions to avoid influencing the results of my data analysis. For instance, my first impression of the main participant was that his dressing style was out 'of this world' and could stem from a narcissistic view. I often thought, "How could an 80-year old man dress like a 16year old boy?". I also assumed that he may have received harsh criticisms from family members and friends. In the past I was censured a number of times for wearing inappropriate clothes; so I presumed that he could be feigning his outward joy while, in fact, suffering from within.

I also suspected he may have had various illnesses due to smoking. Since he helped in the store, alcoholic beverages could come in handy so the thought that he could be drinking often did not slip my mind. My postulations arose from common observations among the elderly who are mostly concerned with medications, indifference towards fashion and complaints about ailing body. Contrastingly, I also thought that he could actually be truly happy because he consistently smiled and dressed up in style for a long time during my morning covert observations. It could be that the main participant may have had unresolved and unspoken inner struggle he needed to face so he can 
understand himself more. My hypotheses pushed me to dig deeper into his own world and listen to the real story. (Alvesson and Skoldberg, 2009.

\section{Data Analysis:}

Data was analyzed using Content Analysis by Berelson (1952) described as a research method in identifying patterns in recorded communication. It points to a systematic collection of data from a set of written oral or visual texts such as interviews, books, pictures, videos, etc. It focuses on interpreting and understanding the texts by categorizing or coding words, themes and concepts within the texts and analyzing the results in order to determine the purposes, messages, and effects behind the content. In the current study, analysis was done to reveal the factors behind the main participant's successful aging and to understand his unusual behavior in old age.

In analyzing the data, I followed Berelson's 9 steps. Step 1 involved verbatim transcription of recorded interviews, photos, videos, artifacts, other archival records while step 2 was about defining the unit of meaning to be coded (i.e., recording the frequency of individual words and phrases, characteristics or portrait of the main participant produced in the texts / visuals, the presence or positioning of images or treatment of themes and concepts). Step 3 was determining the set of categories used for coding which can be objective (i.e., 80-year old male, etc.) or conceptual (factors related to successful aging etc.) while Step 4 involved determining the unit of analysis, i.e., the main participant who appear in the texts coming from his own and other participants' narratives.

The analysis progressed to Step 5 which involved coding or organizing the units of meaning into the previously defined categories done manually and aided by QSRNVivo to speed up the process of counting and categorizing words and phrases (Houghton,Murphy,Meehan, Thomas, Brooker and Casey,2017); and step 6 which was determining and following the rules of coding (i.e. examining each transcript, photo or video and recording the characteristics and factors related to successful aging and along with all words and phrases that are used to describe the main participant). Step 7 completed the coding and examined it further to find patterns and draw conclusions in response to the research question while step 8 revealed results through words and phrases related to successful aging that appeared frequently in most of the data. Finally, step 9 was about using the results to draw conclusions on the factors behind the main participant's successful aging.

\section{Results:-}

The analyzed data generated four major themes considered as factors that contributed to the main participant's successful aging: 1) inner strength 2) stable relationship; 3) quality social interactions; and 4) continuity of youth practices and habits. Relevant parts of the narratives are mentioned to substantiate the discussion and implications.

\section{Theme 1. Inner strength:}

One of the ingredients that contributed to the main participant's successful aging is inner strength manifested by1) strong faith, 2) determination and 3) resilience.

\section{Strong faith:}

Adonis (pseudo) has a strong faith in God shown in his beliefs, convictions, practices and daily routines. He claims that he has a "close relationship with God" (M/P1, No.1, Line 82). It began when his grandmother taught him to pray at the age of 5 . He believes that God allowed him to exist longer without feeling sick. Like the traditional Filipino, he celebrates the feast of a favorite saint every year. He recalls how he held on to sacred medals while his house was being shaken by typhoon Haiyan in 2013 and how he managed to stay calm while people looted the store after the storm. He is convinced that his strong faith in God has saved him and his family from perishing that night (M/P1, Tr. 1, L 82-84).

Aside from celebrating feasts, he recites the rosary every night and keepsin his pocket a picture of the Blessed Mother as an amulet to protect him against evil spirits. Whether it is the veneration of a sacramental object or any form of worship, his strong faith clearly keeps him emotionally stable. This finding is supported by Guyette (2018) who adopted Tornstam's theory of gerotranscendence, which promotes that people who have strong faith and obedience to Godlike the Biblical figures Noah, Abraham and the prophets are likely to attain longevity.

\section{Determination:}

Coming from a poor family, Adonis shares that his childhood was a mixture of hardships and adventures. His family hardly had a decent meal in a day, so at the age of 5 he had to learn how to plow the field. At seven years old he was 
climbing coconuts to make vinegar and coconut wine. When he reached 15, Adonis recalls, "I went to Cebu (a city, south of Philippines) and worked as a waiter in a restaurant but I could hardly speak English, so I came home only to find that my father's land had already been taken by my close relative" (M/P1, Tr. 1, L 24-26). Desperate in taking the land back, he left home in 1969 at the age of 20 and went to another city to look for a lawyer who, by a twist of fate, happened to be the brother of the only woman he would later love in his lifetime.

Poverty was Adonis's nemesis as it stood between him and the woman he loved. Surprisingly, though, Anna (pseudo) chose him over her other suitors and Adonis claimed that this was "because he is handsome" (M/P1, L 3234). This statement matched with a picture of him in his $20 \mathrm{~s}$. The picture showed his face's perfect symmetry, slim body physique and mysterious, dreamy aura in his eyes which attracted Anna's attention. Shortly after, they eloped but were caught; so, they returned home and stayed in Anna's house. Although Anna's family refused to let them marry under official vows, Adonis made a promise to regard her as his wife and remain by her side. Anna's family decided to let them stay in a farm 70 kilometers away from the city. Since Adonis was a farmer, he managed to till the land and earn money for Anna's family. Though he had no rights to the land, he received monthly allowance that he saved to buy parcels of land in his own hometown which later became a source of personal income. This implies Adonis's detachment from Anna's inheritance and the will to find his own source of living.

When Anna's oldest unmarried sister was dying, they were called back to live in Anna's ancestral house to man the store after her death. Adonis blindly obeyed the order and the store has been thriving for the last 5 decades. Earlier, their union was tested when Anna lost her hearing in her 30s and failed to give him a child; yet, Adonis was determined to stay by her side because he considered Anna as the source of his joy and purpose in life (M/P1, Tr. 1, Line 62-63). Scholars believe that finding a clear-cut drive in life, experiencing happiness and contentment are factors in longevity (García and Miralles, 2017; Chiao, et al.,2011).

\section{Resilience:}

Adonis's early adulthood was marred by an incident that left him a deep scar. When Martial Law was declared in the Philippines in 1972, several rebels went to the mountains, in particular near the farm where he and Anna were forced to live. One of the most terrifying experiences he had was when a rebel pointed a gun at his mouth. Although he survived that night, the memory left him with deep trauma and insomnia. In reminiscence, he says with a sigh, "I get up at 12 midnight often recalling the incident. I have become immune to staying up late to watch over the house. I used to keep a shot gun under my pillow. The New Peoples' Army (NPAs) threatened to kill me that night if I did not join them. Fortunately, some government soldiers were patrolling that night. I was spared.” (M/P1, Tr. 1, L 108111).After a national revolution in 1986, he and Anna left the farm to take care of Anna's oldest sister.

He recounts that when Anna's family rejected him and treated him like a mere servant, he remained steadfast, humble and nonretaliatory. He took care of Anna until all of Anna's parents and siblings passed away (M/P1, Tr. 1, L 53-54). Adonis's capacity to recover from difficulties may be attributed to his strong faith and a positive outlook in life in addition to the happiness he derives from being with Anna. According to MacLeod, Musich, Hawkins, Alsgaard and Wicker (2016), resilience can thrive in an environment where faith and deep social relationships merge to enrich living conditions.

\section{Theme 2. Stable relationships:}

The second ingredient in the main participant's journey to successful aging is having stable relationships. This theme has two categories: 1) Love and 2) Loyalty.

Love. It is interesting to note that when the entire set of raw interview data of the main participant was fed to the NVivo software, the largest word in the word cloud was the name of Anna, his wife.This clearly suggests that his world may have revolved around Anna since the day he met her. Adonis openly expresses his love for Anna despite the fact that they are not married either in church or under civil laws. His high regard for her as real wife motivates him to do things like a real husband would do: cook, clean, assist her in the store and even spoon feed her in their old age. Anna's siblings did not have successful marriages so he promised that he will make a difference with Anna and make her marriage last. Anna, on the other hand is more reserved when it comes to expressing feelings but shows hints of jealousy whenever Adonis smiles to a female customer.

When asked whether Anna is jealous of other women, he only answers, "I did not give her any reason to feel that way. I did not want to lose her so I loved her. She is my zest for life. My only love. I just look at beautiful women, 
but I have to be more realistic. I am already old. I still occasionally have a crush on someone, admiring, feeling attracted to her but I would control myself for Anna's sake." (M/P1, Tr.1, L 62-65). These statements suggest two things: the first is his open declaration of love for Anna, which breeds from a commitment he professed when he was young and the other is a longing for reciprocation towards his feelings from the people around him, in particular, women. While Adonis's contemporaries are anxious about old age due to the onset of memory loss, failing health, reduction of funds and medical assistance as well as lack of family and government support (Hedge, Borman and Lammlein, 2006), Adonis thinks more of how women may still find him attractive. By not associating old age on negative thoughts, Adonis avoids health hazards associated with old age such as hypertension, diabetes and other ailments. Adonis just focuses on loving, smiling and looking good.

\section{Loyalty:}

Despite not being allowed to wed Anna, Adonis made up his mind to stick to Anna who was even a few years older than him. There were rumors about Adonis having affairs but he was consistent in saying that he only enjoyed being noticed by other girls but had really no intention of leaving Anna who at an early age lost her hearing and failed to give him a child. A close friend attests to the veracity of his statements saying, "I don't see it myself. I just heard some rumors. I don't even know that he's into girls (laughs). Maybe, there's someone but it's just his imagination."(F/P4, Tr. 4, L 53-54). This was also confirmed by a close male friend saying, "The way I see him as my friend since day one in my 20s, it's just now that there's someone he's in love with and living with." (M/P2, Tr. 2, L 31-32) and he is talking about Anna.

His nephew recounts, "I know that he is friendly towards girls and talks to them at the store; but I haven't heard any story that he has a girlfriend other than Grandma. He once even said to me that it is his love for Grandma that makes him strong." Adonis jokingly added that, "The carabao is the only thing that grows old. The heart remains young" (M/P6, Tr. 6, L 25-27). He meant that his heart still beats for Anna. Adonis's gesture of loyalty to Anna provided stability in his relationship. Although Anna rapidly aged and he himself was surrounded by factors that may have led him to take advantage of Anna, he chose to stay loyal. In fact, he does not go near the drawer at the store but he helps Anna as if the store is his. This observation is supported by Lam's and Chan's (2015) finding that active continuous cognitive engagements like doing things together in the family can promote a healthy mind and loving relationships.

\section{Theme 3. Quality Social Interactions:}

Another important factor that delayed the main participant's aging process is his active social networking evidenced by his 1) congeniality and 2) love for music and dance.

\section{Congeniality:}

Adonis's closest friends and family members agree that he is friendly and easy to be with. His nephew describes him as "Funny, friendly, energetic, bubbly and always in a happy mode" (M/P6, Tr. 2, L 13-14) while a close friend says, "He handles people well" M/P3, Tr. 3, L 20; 27). From the day I encountered Adonis face to face, I have noticed his smiling face and vibrance. He smiles and laughs most of the time and feels excited talking to others (Memo \#1,11/11/17, L 47, 48; 50). He says he loves to drink with friends but this one big favorite activity is also Anna's nemesis. "She does not like seeing him drunk" (F/P5, Tr. 5, L 54;59) "because he tends to behave wildly" according to a close friend (F/P7, Tr. 7, L 65-66). However, Adonis says, he feels dead without drinks because this is his way of connecting to his friends. His congeniality is, as Tolle aptly calls, an effective and a powerful way of grounding him to the present moment (Davis, 2017).

\section{Love for music and dance:}

It is interesting to note that among his contemporaries, only Adonis remains interested in singing and dancing chacha, boogie, tango and swing. He willingly sings and dances in public. In fact, in one of my visits, he danced with me in front of the store. He used to perform in a local TV show three years ago (M/P1, Tr. 1, L 209-212; Tr 12 L6769). This may explain his joyful countenance and zest for life. Adonis says he started singing when he was a little boy. He tagged along with cousins who serenaded girls using the guitar. After trying so hard he learned how to play it and got his own Gibson guitar in his early teens. He then joined 'harana' (serenade) with cousins as guitarist and later on formed his own band with him as lead vocalist. (M/P1, Tr. 1, L 223-229).

He went to various places just to dance during the eve of a town fiesta (celebrating feast of a saint). He recalls how he used to envy his older cousins for being able to dance with beautiful girls; hence, as soon as he learned to dance 
and sing, he was unstoppable. His youthful looks, he says, is also caused by his love for music and dance. This supports a finding that the arts enhance cognitive reserve in aging which may help avert mild cognitive impairmentby solidifying cortical gray matter that preserves mental functions even in old age (Porat, Goukasian, Hwang, Zanto, Do, Pierce, and Apostolova, 2016).

Theme 4. Continuity of youth practices and habits:

Aging can be delayed when there is continuity of 1) healthy habits, 2) daily grooming and 3) healthy self-esteem.

\section{Healthy habits:}

Adonis believes that keeping himself physically fit is essential to achieving a youthful look. Even at the age of 80, Adonis says, "I still jog to the market in the early morning to buy food for the family and other stuff to be sold at the store" (M/P1, Tr. 8, L 310-312; Trans 6, L23-24). He says that he has been doing this since he was young. With regular exercise it was not surprising when he said, "I have never been hospitalized. I have no medicine for maintenance of high blood pressure or diabetes (M/P1, Tr. 8, L264-265). He added that he gets anti-flu shots on certain occasions and gets regular checks of his blood pressure. His niece-in-law confirms saying, "He seems always happy and energetic so I have not noticed him getting seriously ill” (M/P6, Tr. 6, L97-99; M/P1, Tr. 12, L 80-82; F/P7, Tr. 7, L65-66).

Contrary to earlier claims of living healthy, Adonis honestly admitted that he still smokes and drink. In fact, he used to smoke 4 sticks a day. He started smoking at the age of 9 when a friend said it tasted sweet. He confesses, "I seldom smoke now but I really find it hard to totally quit smoking" (M/P1, Tr. 8, L197-199; Tr. 1, L92-93). However, he denied experiencing serious smoking or drinking-related illnesses. The people closest to him confirmed that he looks healthy at 80 and hardly had any check up. Specifically, Participant 5 observed, "Since the first time I saw him, I haven't heard of him having headaches, or other common illnesses we normally have" (F/P5, Tr. 5, L4243). His nephew who monitors his blood pressure considers it a miracle that Adonis's blood pressure is normal most of the time. He reports that Adonis catches colds occasionally but there has been no reported serious illness (F/P5, Tr. 5, L20-22).

Recent findings show that when people think and behave as if they are healthy, they will likely recover fast even if they have chronic illness (Tzioumis, Avila and Adair, 2019). This finding implies the link between Adonis's mental health and his cognitive attitude and behavior.

\section{Daily grooming:}

Every morning for the last decade, while passing by his store, I have noticed Adonis' style of dressing like that of Elvis Presley, John Lennon, cow boy, celebrity or simply the typical teen who wears goggles and fancy jewelry in addition to very short pants that almost reach his tail bone. He normally stands or sits in front of the store while joyfully chatting with bystanders, friends and customers (Memo, L51-55). The wife of his closest friend shares her thoughts about his style of dressing saying, "It looks good on him. It's fine," but when asked if she would encourage her husband to do the same, she gave an explosive laughter with a stern "No, because it's unnatural and ridiculous." (F/P4, Tr. 4, L20-23). She was trying to suggest that in the eyes of young and old people, dressing up like a teen when you are 70 or 80 years old is unacceptable; yet, for Adonis, it seemed normal. She finds no issues.

Meanwhile, another friend remarked, "He has a good taste in choosing clothes," which implies the enormous amount of time Adonis devotes in choosing the right combinations of colors, textures and designs in clothes (M/P3, Tr. 3, L15). One neighbor recalled asking Adonis why he always wears fashionable clothes. Adonis replied that he is getting old so he wants to wear his best clothes every day. To quote, he said, "If teenagers nowadays are fashionable, I want to upgrade my fashion trends as well." (F/P5, Tr. 5, L16-19). In addition, he actually thinks it is good to die 'handsome.'

Adonis's nonconformant behavior clearly contradictsa collective behavior of older people losing interest in fashion and trend, choosing to discard excess clothing and adopting simple lifestyles with religious meaning (Ro, 2019). Another study also revealed that older men are unlikely to talk about anti-aging products or anything related to enhancing their appearance (Calasanti, King, Pietilä andOjala, 2016). However, for Adonis, it is not the way to live in old age. He does not want to burden anyone looking for clothes for him when he dies so he prepares for it on a daily basis. To quote, he said, "That's me. Just like how I create my own styles, I want to be unique and that's how I 
want to look like when I'm already lying in my coffin. I just want to look good and happy until the end" (M/P1, Tr.9, L57-58).

\section{Healthyself-esteem:}

Apart from healthy habits and daily grooming, Adonis feels good about himself, considers himself attractive and deserving of respect from others. During the interview, he expressed his desire to stand out among his contemporaries. He says he doesn't want to be outdone in fashion by anyone else. This may sound narcissistic but when asked to elaborate further, he replied, “I just believe I am very attractive. I don't know about other people's opinions of me but when I face the mirror, I really look handsome. I believe this is the reason why my wife chose me over her other suitors; so, I intend to keep this image (M/P1, Tr. 9, L13-14). Noticeably, his last statement suggests an underlying reason behind his manifest behavior that he himself is unaware of.

Moreover, he confesses that being called 'guwapo' (handsome) by friends and family members makes him happy. To him, being happy keeps him healthy and allows him to take care of Anna. He does not rely on external validations to propel him to sustain activities. He narrates, "Even when I am at home and there is no one else around, I try to look my best. I just enjoy doing this. It makes me happy. This pair of boots is only removed when I'm taking a bath or at night when I'm about to sleep. Even during lunch, I still wear my boots" (M/P1, Tr. 10, L189-193). Orth (2017) considers this behavior as highly constructive. He stresses that self-esteem is relative across life spans and normally declines in old age but those who are able to sustain it reap cognitive and affective benefits. Thus, Adonis's healthy self-esteem has strengthened his stable self-concept and lifestyle over the years.

\section{Discussion:-}

The themes generated in this study provide various angles in explaining Adonis's intrinsic path to successful aging. In this section, I point out significant facts in Adonis's life to substantiate the main analytic view that the main participant attained successful aging not because he deliberately wanted it but because of other factors that interacted with age, interest, economic status and significant events in the main participant's life. The proceeding paragraphs explore varying angles of examining the main participant's journey.

Adonis's vision of 'wearing nice clothes, playing music and dancing was influenced by an experience he had with cousins when he was 5 years old. He said that the enduring memory of that brief encounter was like a fierce wind that propelled him to embark on a journey towards becoming one of the handsomest and youngest-looking and highly spirited 80-year old man in his generation. This may be termed as sustained interest with corresponding consistent action that becomes stable and accessible after it is repeatedly done for a long period of time (Sheeran, Godin, Conner, and Germain, 2017). Adonis constructed a culture that subsequently delayed his aging process and kept him mentally healthy in later years despite his devastating trials and the presence of some harmful habits such as occasional smoking and drinking (Havighurst, 1961).

On the surface, one may see the original intention stemming from a sense of financial lack since he frequently mentioned that poverty was his biggest challenge. However, this may just be manifest data. The latent reason could be explained by his genetic predisposition for liking clothes, music and dancing that just needed a stimulus to awaken. There are currently no other studies supporting this observation except that of Esposito, Truzzi, Setoh, Putnick, Shinohara, and Bornstein (2017) emphasizing that genetic and experiential factors influence a person's ability to perceive and understand feelings and viewpoints. At an early age, Adonis felt the beat for fashion, music and dance. Had he been well-off he could have attained more than just being the vocalist of a local band in his teens and a singer in a local TV show for senior citizens in his 70s. This implies the importance of providing equal opportunities for children to discover their talents and gifts at an early age and to sustain that support until they reach their maximum potential.

Perhaps the most widely known prescription for successful aging is linked to healthy physical and mental functioning. Lam and Chan (2015) assert that lifestyle factors can modify cognitive function in later life. In Adonis' case, his interest in clothes and the arts paved the way for a renewed life structure. Adonis undeniably carried painful residues of early childhood experiences into adolescence and early adulthood only to make them his cornerstone, not to dwell on them too long. Earlier he associated his lowly status to the refusal of Anna's family to grant them an official wedding. For a long time he struggled to remove himself from poverty in order to win Anna's family. But as Anna decided to stick to him and with the passing away of Anna's entire family, he realized the uselessness of blaming his poverty over his challenging circumstances. Adonis's negative mental dialogue, 
according to Crous (2017) may have been brought about by material deprivation in early childhood, which can result in a low psychological well-being and paranoia (PWB) in later life.

Worth-noting is Adonis's alchemic attitude that converts his mental dialogues into positive energy. Instead of being discouraged, he kept himself busy trying to look his best. On the surface, being attractive may have been his end goal, yet, the root of everything may have been to safeguard the image that his wife considered in choosing him over other affluent suitors. Beyond looking handsome in Anna's eyes, Adonis said he wants death to find him welldressed so that his family will not bother looking for his burial attire. This implies that although he is in the world, he is not tied to it. His behavior manifests inner peace which Tolle calls 'living in the here and now' (Davis, 2017).

\section{Limitations and Further Research:}

Although the interviews of the main participant and the rest of the people closest to him served to provide reliable data, it would have added more strength had Anna joined the interviews. However, this was beyond my control since Anna has hearing impairment. The information about her life came mostly from the main participant, her niece and nephew who lived with her since she was young. I recognize the greater validity of primary data; hence, I consider this a weakness in the study.

For further research, I recommend that a collective study be conducted of elderly participants belonging to the marginalized groups but have attained successful aging.

\section{Conclusion and Implication:-}

Overall, this study unearthed 4 elements that contribute to successful aging such as: 1) inner strength 2) stable relationship; 3) quality social interactions; and 4) continuity of youth practices and habits. It confirms theories and findings advocating that sustained good habits and activities from early life can guard humans from the pitfalls of old age (Havighurst, 1961; Maddox, 1968; and Atchley, 1999). It highlights an interesting point in the study wherein, on the surface, the participant's ostentatious display of style and fashion misconstrued as shallow vanity appears to be just the manifest data. The latent meaning of his unusually nonconformant behavior points to an artistic way of navigating through life's various realities. The main protagonist is defying the genetics of age by using the mind to revert matter; thus, delaying his aging process. It strengthens the idea that successful aging is not something attainable by only a few because it is not bound by the limits of status, creed, color or race. Successful aging is a creative experience unique to every human in every culture and context.

\section{Acknowledgment:-}

I am deeply indebted to the following: the main participant, his family members, close friends and neighbors who shared their precious time during my visits; my family and friends for their love and support; and above all, I praise God who enabled me to finish this work.

\section{References:-}

1. Alvesson, M., \&Skoldberg, K. (2009). positivism, social constructionism, critical realism: Three reference points in the philosophy of science. Reflexive methodology: New vistas for qualitative research, 15-52.

2. Akhtar, S., \& O'Neil, M. K. (Eds.). (2018). On Freud's Beyond the pleasure principle. Routledge.

3. Ashmore, M. (1989). The reflexive thesis: Wrighting sociology of scientific knowledge. University of Chicago Press.

4. BaAnton, S. D., Woods, A. J., Ashizawa, T., Barb, D., Buford, T. W., Carter, C. S., \& Dotson, V. (2015). Successful aging: advancing the science of physical independence in older adults. Aging research reviews, 24, 304-327.

5. Atchley, R. C. (1971). Retirement and leisure participation: Continuity or crisis?. The Gerontologist, 11(1_Part_1), 13-17.

6. Atchley, R. C. (1989). A continuity theory of normal aging. The gerontologist, 29(2), 183-190.

7. Atchley, R. C. (1999). Continuity and adaptation in aging: Creating positive experiences. Johns Hopkins University Press.

8. Baxter, P., \& Jack, S. (2008). Qualitative case study methodology: Study design and implementation for novice researchers. The qualitative report, 13(4), 544-559.

9. Berelson, B. (1952). Content Analysis in Communication Research. Glencoe: Free Press. p. 18. 
10. Calasanti, T. (2015). Combating ageism: How successful is successful aging?.repe The Gerontologist, 56(6), 1093-1101.

11. Calasanti, T. (2019). On the intersections of age, gender and sexualities in research on aging. Intersections of aging, gender, sexualities: Multidisciplinary international perspectives, 13.

12. Calasanti, T., \& Giles, S. (2018). The challenge of intersectionality. Generations, 41(4), 69-74.

13. Calasanti, T., King, N., Pietilä, I., \&Ojala, H. (2016). Rationales for anti-aging activities in middle age: aging, health, or appearance? The Gerontologist, 58(2), 233-241.

14. Carver, L. F., \& Buchanan, D. (2016). Successful aging: considering non-biomedical constructs. Clinical interventions in aging, 11, 1623.

15. Cheng ST. (2015) Demographic and Family Trends in Asia. In: Cheng ST., Chi I., Fung H., Li L., Woo J. (eds) Successful Aging. Springer, Dordrecht

16. Cheng ST., Chi I., Fung H., Li L., Woo J. (eds) (2015). Prevention of Cognitive Decline in Later Life. In: Successful Aging. Springer, Dordrecht

17. Cheng ST., Fung H.H., Li L.W., Li T., Woo J., Chi I. (2015) Successful Aging: Concepts, Reflections and Its Relevance to Asia. In: Cheng ST., Chi I., Fung H., Li L., Woo J. (eds) Successful Aging. Springer, Dordrecht

18. Cheng ST., Li L.W., Woo J., Chi I., Fung H.H. (2015) Successful Aging in Asia: A Concerted Effort of the State, the Family, and the Individual. In: Cheng ST., Chi I., Fung H., Li L., Woo J. (eds) Successful Aging. Springer, Dordrecht

19. Chiao, C., Weng, L., \& Botticello, A. (2011). Social Participation Reduces Depressive Symptoms Among Older Adults: An 18-year longitudinal analysis in Taiwan. BMC Public Health, 11, 292

20. Cosco, T. D., Stephan, B. C., Brayne, C., Muniz, G., \& CFAS, M. (2017). Education and successful aging trajectories: A longitudinal population-based latent variable modelling analysis. Canadian Journal on Aging/La Revue canadienne du vieillissement, 36(4), 427-434.

21. Cosco, T., Prina, A., Perales, J., Stephan, B., \& Brayne, C. (2014). Operational definitions of successful aging: A systematic review. International Psychogeriatrics, 26(3), 373-381. doi:10.1017/S1041610213002287

22. Creswell, J. W. (2014). Research design: qualitative, quantitative, and mixed methods approaches. 4th ed. Thousand Oaks, California: SAGE Publications.

23. Crous, G. (2017). Child psychological well-being and its associations with material deprivation and type of home. Children and Youth Services Review, 80, 88-95.

24. Davis, P. (2017). Oprah \& Eckhart Tolle-A New Earth, Feeding the Body with Spiritual Energy \& Overcoming Obesity. August 7.

25. Esposito, G., Truzzi, A., Setoh, P., Putnick, D. L., Shinohara, K., \& Bornstein, M. H. (2017). Genetic predispositions and parental bonding interact to shape adults physiological responses to social distress. Behavioural brain research, 325, 156-162.

26. Flick, U. (2018). Designing qualitative research. Sage.

27. García, H., \&Miralles, F. (2017). Ikigai: The Japanese secret to a long and happy life. Penguin.

28. García-Lara, J. M. A., Navarrete-Reyes, A. P., Medina-Méndez, R., Aguilar-Navarro, S. G., \& Avila-Funes, J. A. (2017). Successful aging, a new challenge for developing countries: The Coyoacán Cohort. The journal of nutrition, health \& aging, 21(2), 215-219.

29. Goveas, J. S., Rapp, S. R., Hogan, P. E., Driscoll, I., Tindle, H. A., Smith, J. C., ... \&Yaffe, K. (2016). Predictors of optimal cognitive aging in $80+$ women: the Women's Health Initiative Memory Study. Journals of Gerontology Series A: Biomedical Sciences and Medical Sciences, 71(Suppl_1), S62-S71.

30. Guyette, F. (2018). Successful aging: Social theory, scripture, church teaching. Journal of Religion, Spirituality \& Aging, 30(3), 199-211.

31. Hancock, D. R., \&Algozzine, B. (2016). Doing case study research: A practical guide for beginning researchers. Teachers College Press.

32. Havighurst, R. J. (1963). Successful aging. Processes of aging: Social and psychological perspectives, 1, 299320 .

33. Hedge, J. W., Borman, W. C., \&Lammlein, S. E. (2006). The aging workforce: Realities, myths, and implications for organizations. American Psychological Association.

34. Houghton, C., Murphy, K., Meehan, B., Thomas, J., Brooker, D., \& Casey, D. (2017). From screening to synthesis: using nvivo to enhance transparency in qualitative evidence synthesis. Journal of clinical nursing, 26(5-6), 873-881.

35. Kang SY., Kim J. (2015) Successful Aging and Economic Security Among Older Koreans. In: Cheng ST., Chi I., Fung H., Li L., Woo J. (eds) Successful Aging. Springer, Dordrecht 
36. Katagiri K., Wakui T. (2015) The Road to Successful Aging: Older Adults and Their Families in Japan. In: Cheng ST., Chi I., Fung H., Li L., Woo J. (eds) Successful Aging. Springer, Dordrecht

37. Kernisan, L. (2016). Promises and pitfalls: Technology and the future of delivering eldercare. Generations, 40(1), 92-98.

38. Koff, W. C., \& Williams, M. A. (2020). Covid-19 and immunity in aging populations-a new research agenda. New England Journal of Medicine.

39. Lam L.C.W., Chan W.C. (2025) Greenberg, T. M. (2016). Narcissistic aspects of aging and illness. In Psychodynamic perspectives on aging and illness (pp. 69-89). Springer, Cham.

40. Lasch, C. (2018). The culture of narcissism: American life in an age of diminishing expectations. WW Norton \& Company.

41. Li L.W., Zhang J. (2015) Challenges to Successful Aging in Transitional China. In: Cheng ST., Chi I., Fung H., Li L., Woo J. (eds) Successful Aging. Springer, Dordrecht

42. Lin, P. S., Hsieh, C. C., Cheng, H. S., Tseng, T. J., \&Su, S. C. (2016). Association between physical fitness and successful aging in Taiwanese older adults. PloS one, 11(3), e0150389.

43. Löckenhoff C.E., Lee D.S., Buckner K.M.L., Moreira R.O., Martinez S.J., Sun M.Q. (2015) CrossCultural Differences in Attitudes About Aging: Moving Beyond the East-West Dichotomy. In: Cheng ST., Chi I., Fung H., Li L., Woo J. (eds) Successful Aging. Springer, Dordrecht

44. Lok, K.YW., Chan R.SM., Woo J. (2015) The Role of Nutrition in Successful Aging. In: Cheng ST., Chi I., Fung H., Li L., Woo J. (eds) Successful Aging. Springer, Dordrecht

45. Loue, S. (2008). Encyclopedia of aging and public health. Springer Science \& Business Media.

46. Lucas, H. M., Lozano, C. J., Valdez, L. P., Manzarate, R., \&Lumawag, F. A. J. (2018). A grounded theory of successful aging among select incarcerated older Filipino women. Archives of gerontology and geriatrics, 77 , 96-102.

47. Lucas, H. M., Lozano, C. J., Valdez, L. P., Manzarate, R., \&Lumawag, F. A. J. (2018). A grounded theory of successful aging among select incarcerated older Filipino women. Archives of gerontology and geriatrics, 77 , 96-102.

48. MacLeod, S., Musich, S., Hawkins, K., Alsgaard, K., \& Wicker, E. R. (2016). The impact of resilience among older adults. Geriatric Nursing, 37(4), 266-272.

49. Orb, A., Eisenhauer, L., \&Wynaden, D. (2001). Ethics in qualitative research. Journal of nursing scholarship, 33(1), 93-96.

50. Orth, U. (2017). The lifespan development of self-esteem. In Personality development across the lifespan (pp. 181-195). Academic Press.

51. Pelicioni, P. H., \& Lord, S. R. (2020). COVID-19 will severely impact older people's lives, and in many more ways than you think. Brazilian Journal of Physical Therapy.

52. Porat, S., Goukasian, N., Hwang, K. S., Zanto, T., Do, T., Pierce, J., ... \& Apostolova, L. G. (2016). Dance experience and associations with cortical gray matter thickness in the aging population. Dementia and geriatric cognitive disorders extra, 6(3), 508-517.

53. Repetti, M., \&Calasanti, T. (2018). 'Since I retired, I can take things as they come. For example, the laundry': gender, class and freedom in retirement in Switzerland. Aging\& Society, 38(8), 1556-1580.

54. Ridder, HG. Bus Res (2017) The theory contribution of case study research designs 10 : 281. https://doi.org/10.1007/s40685-017-0045-z

55. Ro, J. (2019). Fashion Attitudes towards and Images of Old Age Represented in Films. International Journal of Costume and Fashion, 19(1), 87-104.

56. Rowe, J. W., \& Kahn, R. L. (1997). Successful aging. The gerontologist, 37(4), 433-440.

57. Rowe, J. W., \& Kahn, R. L. (2015). Successful aging 2.0: Conceptual expansions for the 21st century. The Journals of Gerontology: Series B, 70(4), 593-596.

58. Sanchez, N. (2016). Exploring the journey towards successful aging in the Philippines: A mixed method study. researchbank.acu.edu.au

59. Sanchez, N. K. (2019). How Social Pensions and Income Contributes to Successful Aging? A Mixed Method Study.

60. Schul, R; Noelker L.; Rockwood, K; L. Sprott, R. eds. (2006). "Continuity Theory". Encyclopedia of Aging. 1 (4th ed.). Springer Publishing Company. pp. 266-268. ISBN 0-8261-4843-3

61. Sheeran, P., Godin, G., Conner, M., \& Germain, M. (2017). Paradoxical effects of experience: Past behavior both strengthens and weakens the intention-behavior relationship. Journal of the Association for Consumer Research, 2(3), 309-318.

62. Stake, 2005 (case study) 
63. Tamborini, C. R., \& Kim, C. (2020). Are You Saving for Retirement? Racial/Ethnic Differentials in Contributory Retirement Savings Plans. The Journals of Gerontology: Series B, 75(4), 837-848.

64. Thoma, M., Kleineidam, L., Maercker, A., Maier, W., \& Wagner, M. (2017). Validation of different successful aging constructs and comparison of their predictors. Innovation in Aging, 1(Suppl 1), 1184.

65. Tolle, E. (2008). A New Earth: Awakening to Your Life's Purpose (Oprah's Book Club, Selection 61).

66. Tzioumis, E., Avila, J., \& Adair, L. S. (2019). Determinants of Successful Aging in a Cohort of Filipino Women. Geriatrics, 4(1), 12.

67. UNESCO, E. (2015). Global action programme on education for sustainable development information folder.

68. UNESCO. (2020). Adverse consequences of school closures. Geneva: UNESCO

69. United Nations, Department of Economic and Social Affairs, Population Division. (2009). World population prospects: The 2008 revision highlights. New York: United Nations. Retrieved from: www.un.org/esa/population/publications/ wpp2008/wpp2008_highlights.pdf. Related databases last updated March 9, 2009, retrieved May 15, 2009, from: http://esa.un.org/unpp.

70. Willcox, B., Chen, R., Masaki, K., Willcox, D. C., Allsopp, R., \& Donlon, T. (2018). Can We Age Successfully? Measures of Comorbidity and Healthy Aging in the Kuakini Honolulu Asia Aging Study. Innovation in Aging, 2 (Suppl 1), 752.

71. Woo J., Yau F., Yu R. (2015) Role of Physical Activity in Successful Aging. In: Cheng ST., Chi I., Fung H., Li L., Woo J. (eds) Successful Aging. Springer, Dordrecht

72. Yeung D.Y., Ho H.C.Y. (2015) Psychological Adaptation of Older Workers: Findings from the Western and Eastern Countries. In: Cheng ST., Chi I., Fung H., Li L., Woo J. (eds) Successful Aging. Springer, Dordrecht. 